\title{
Corpo e psique: da dissociação à unificação — algumas implicações na prática pedagógica
}

\author{
Lucia Helena Pena Pereira \\ Universidade Federal de São J oão del-Rei
}

\section{Resumo}

Este trabalho tem por objetivo analisar a unicidade corpo/psique e os bloqueios de expressão pessoal, provenientes da dissociação dessas dimensões, que dificultam as atividades profissionais e a própria vida. A formação do professor exige mais que a aquisição de conteúdos e técnicas de ensino. Transformações mais profundas na prática pedagógica implicam uma mudança de atitude dos educadores, uma nova postura diante da vida e da educação, não apenas uma mudança cognitiva com a aquisição de conhecimentos, mas também mudanças emocional, corporal e espiritual, uma aprendizagem da integração das várias dimensões do ser humano. É necessário saber como superar ou minimizar bloqueios que a vida exigiu como proteção como nos mostram os estudos de Wilhelm Reich e alguns de seus continuadores - Alexander Lowen, Stanley Keleman e David Boadella -, que dão fundamentação teórica a esta pesquisa. É preciso saber como criar possibilidades de transformar padrões que são adquiridos pela formação acadêmica e que acabam por se cristalizar como evidenciam estudos pedagógicos aqui considerados. Uma das formas viáveis para tal são as atividades expressivas, dentre elas as atividades lúdicas e de arte- educação. As relações se constituem no ambiente social, o processo de crescimento se dá no contato com o outro, na percepção das diferenças, na aceitação da multiplicidade de pensamentos, na avaliação de seu próprio fazer. As teorias aqui consideradas são significativas para os estudos na área da Educação na medida em que apontam possibilidades de um novo olhar para a prática de sala de aula e as relações que nela se estabelecem.

\section{Palavras-chave}

Corpo-psique - Prática pedagógica - Atividades expressivas Autocuidado.

\footnotetext{
Correspondência:

Lucia Helena Pena Pereira

Rua Dr. Martins Ferreira, 171 ap. 101

36307-230 - SãoJ oão del-Rei - MG

e-mail: luciahelenapp@uol.com.br
} 


\title{
Body and psyche: from dissociation to unification - implications for pedagogical practice
}

\author{
Lucia Helena Pena Pereira \\ Universidade Federal de São J oão del-Rei
}

\begin{abstract}
The objective of this work is to analyze the body/psyche unity and the hindrance to personal expression that arises from the dissociation of these two dimensions, complicating professional activities and life itself. The education of a teacher requires more than just the acquisition of contents and teaching techniques. More profound changes in the pedagogical practice entail a change of attitude from educators, a new stance before life and education, and not merely a cognitive change with the acquisition of knowledge, but also emotional, bodily and spiritual changes, learning to integrate the various dimensions of the human being. It is necessary to know how to overcome or minimize barriers that life imposed as protections, as shown by the works of Wilhelm Reich and his followers - Alexander Lowen, Stanley Keleman and David Boadella -, which constitute the theoretical background for the present study. It is necessary to know how to create opportunities to transform patterns acquired in the academic formation, which eventually congeal, as disclosed by the psychological investigations considered here. One possible way to do that is through expressive activities, such as ludic activities and arteducation. Relations are constituted in the social environment; the process of growth takes place in the contact with the other, in the perception of the differences, in accepting the multiplicity of thinking, in evaluating one's own doings. The theories considered here are meaningful for the studies in the field of Education insofar as they point to the possibility of a new outlook on the classroom practices and the relations established therein.
\end{abstract}

\section{Keyw ords}

Body-psyche - Pedagogical practice - Expressive activities - Self-care.

Contact:

Lucia Helena Pena Pereira

Rua Dr. Martins Ferreira, 171 ap. 101

36307-230 - São J oão del-Rei - MG

e-mail: luciahelenapp@uol.com.br 
0 programa de pesquisa que tem sido desenvolvido ao longo de minha caminhada acadêmica tem como enfoque central a investigação das dificuldades de expressão criativa e das relações interpessoais que trazem empecilhos para 0 cotidiano da sala de aula e à própria vida. Vivendo os desafios da formação de futuros professores, minha pesquisa de doutoramento me levou a aprofundar estudos na relação indissociável entre pensamento, sentimento e ação, que nos ajudam a refletir sobre as dificuldades experienciadas no processo educacional, a entender alguns de seus porquês, a buscar formas de minimizá-las e a superar obstáculos.

Ensinar e aprender são aspectos fundamentais da ação docente que não se dissociam. $\mathrm{Não}$ há ensino se não há aprendizagem. $\mathrm{Na}$ verdade, o educador cria condições para que a aprendizagem ocorra, pois, sozinho, será incapaz de gerar o processo de construção de conhecimento do aluno. Freire enfatiza que, "nas condições de verdadeira aprendizagem, os educandos vão se transformando em reais sujeitos da construção e da reconstrução do saber ensinado, ao lado do educador, igualmente sujeito do processo". Se não houver um saber apreendido na sua razão de ser, ou seja, apreendido pelos educandos, não poderemos falar de um saber ensinado. Essas condições, de que nos fala Freire (2004),

[...] implicam ou exigem a presença de educadores e educandos criadores, instigadores, inquietos, rigorosamente curiosos, humildes e persistentes. (p. 26)

Isso implica um envolvimento intelectual, corporal e emocional.

Enquanto nos mantivermos aprisionados ao modelo chamado tradicional, que vem se perpetuando ao longo dos séculos, não haverá espaço para mudanças mais profundas nas práticas pedagógicas. 0 intelecto é uma das dimensões fundamentais do ser humano, entretanto, se tomada dissociadamente das outras dimensões - a emocional, a corporal e a espi- ritual -, gera limitações ao desenvolvimento do ser humano como enfatizam Damásio (1996) e Maturana (2001).

0 objetivo deste texto é abordar a questão da unicidade corpo-psique como aspecto essencial para a formação do ser humano. Corpo e psique são faces do ser humano em sua totalidade, o que implica que o corpo expressa os afetos da psique e a psique expressa a fluidez ou a rigidez do corpo.

\section{o problema e uma possibilidade vis lumbrada}

Considerando-se que a racionalidade, 0 corpo, a emoção, a ludicidade, o imaginário e a espiritualidade são importantes para a integridade do ser humano, minhas pesquisas têm buscado a ampliação desse campo de conhecimentos e possibilidades de intervenção para que futuros educadores, ou aqueles que já exercem a profissão, invistam em um permanente processo de autoformação e de melhor relacionamento consigo mesmos e com o outro para que possam atuar com mais abertura em sua prática pedagógica, beneficiando seus educandos. Soma e psique são uma totalidade e a atitude corporal interfere no processo de construção da ordem social e nos processos de libertação, autonomia e consciência do indivíduo, como comprovam as teorias de Wilhelm Reich e de seus continuadores. Essa constatação traz uma questão fundamental: se houver excessiva valorização da racionalidade em detrimento da corporeidade, do sensível, do lúdico e da emoção, teremos possibilidades de exercer nosso ofício de educadores com uma visão integrada do ser humano?

É importante pensarmos em uma educação voltada para a formação integral do ser humano, que leve em consideração seus pensamentos, seu corpo, seus sentimentos e sua espiritualidade, que o capacite a viver numa sociedade pluralista em constante processo de mudança. Isso requer, como observa Moraes (1997), além do desenvolvimento 
[...] das dimensões cognitiva e instrumental, o trabalho, também, da intuição, da criatividade, da responsabilidade social, juntamente com os componentes éticos, afetivos, físicos e espirituais. (p. 211)

Assim, a educação, como propõe o relatório da UNESCO, assinado por Delors (2001), deverá oferecer meios que ajudem o aluno a aprender a aprender, aprender a pensar, a conviver e a amar. Uma educação que o ajude a formular hipóteses, criar possibilidades, tomar decisões. Uma educação que considere não apenas o plano individual, mas também o plano coletivo, uma vez que somos indivíduos e seres sociais, aprendendo e constituindo-nos na relação com o mundo que nos cerca.

\section{Procedimentos metodológicos}

A pesquisa que deu origem a este trabalho foi estruturada em duas partes. Primeiramente, a pesquisa bibliográfica permitiu a fundamentação teórica da proposta apresentada. Foram analisadas as teorias de William Reich e de alguns de seus continuadores - Alexander Lowen, Stanley Keleman e David Boadella -, que dão sustentação à proposta desenvolvida; foi definida a visão de atividades expressivas, sendo abordados estudos pedagógicos que Ihe dão corpo; foram traçadas as relações com as teorias centrais para que se estabelecessem os elos fundamentais de transferência das teorias psicossomáticas para a prática pedagógica; também foram analisadas possibilidades e dificuldades de sua utilização na formação de educadores.

A pesquisa-ação foi o método considerado mais adequado para os estudos desenvolvidos, uma vez que houve uma ação planejada com objetivo de minimizar limitações profissionais, solucionar, na medida do possível, dificuldades existentes, ou ainda, no limite das possibilidades, promover transformações pessoais dos educadores envolvidos. Como considera Michel Thiollent (2002), a pesquisa-ação não se constitui apenas pela ação ou participação, mas deve produzir conhecimentos, permitir a aquisição de experiência, contribuir para a reflexão ou avançar debates sobre as questões abordadas, que deverão ser divulgadas posteriormente. Assinala ainda esse autor que, com a pesquisa-ação, os pesquisadores desejam investigações em que "as pessoas implicadas tenham algo a 'dizer' e a 'fazer'", ou seja, que tenham um papel ativo nas diferentes etapas do processo investigativo, o que é bem diferente

[...] de simples levantamento de dados ou relatórios a serem arquivados. Com a pesquisa-ação os pesquisadores pretendem desempenhar um papel ativo na própria realidade dos fatos observados. (p. 16)

0 cuidado com esses aspectos esteve presente nesta pesquisa, em um trabalho conjunto da pesquisadora e dos participantes.

A intervenção formativa com os educadores consistiu da participação em um curso de extensão, realizado na Faculdade de Educação - FACED, da Universidade Federal da Bahia, em que teoria e prática foram desenvolvidas, totalizando 80 horas de atividades, e o subseqüente acompanhamento aos professores em suas escolas, que proporcionaram uma coleta de dados numerosos: relatos da percepção das vivências escritos após cada aula; observações da pesquisadora durante o curso; depoimentos dos participantes durante todo o processo; entrevistas inicial e final; observações em sala de aula; e entrevistas com os alunos dos 18 professores participantes da pesquisa que lecionavam disciplinas diferenciadas.

Os participantes do curso foram selecionados tendo presentes os seguintes pré-requisitos: os educadores deveriam estar em sala de aula, atuar de 5a a 8a série do Ensino Fundamental ou Ensino Médio, e ter disponibilidade para participar da pesquisa.

Antes de apresentar a visão dos autores fundantes da relação corpo-psique como suporte teórico da investigação, julgo significativo fazer algumas considerações sobre a pesquisa 
científica como prática instituída ao longo desse tempo de quase um século que se passou desde que Wilhelm Reich iniciou seus estudos, e sobre algumas pesquisas nesse campo da relação corpo-mente que se constituem em possibilidades de enriquecimento das investigações que venho aprofundando em relação a suas implicações pedagógicas. Após essas apresentações, analisarei algumas possibilidades de flexibilizar as couraças, que resultam na dissociação corpo-psique, chegando a algumas considerações finais que apontam a unificação corpo-psique como um caminho viável para a formação integral do ser humano.

\section{A questão corpo-psique no â mbito da investigação}

científic a : a compreensão sobre a unicidade

0 controle dos dados pela ciência, que buscava eliminar incertezas, dúvidas, imprecisões, era e continua sendo uma forma de poder, uma forma de dominar e controlar o mundo. No entanto, a ciência hoje se depara com 0 incerto, 0 indeterminado, o complexo. A infalibilidade e unicidade da ciência se transformaram em um mito, embora quebrar os padrões instituídos e ser original exijam fôlego, coragem, significando enfrentar críticas e pressões.

Capra (1988) observa que o começo do século XX presenciou uma grande transformação da ciência. Da concepção mecanicista de Descartes e Newton, passou-se para uma visão sistêmica. Tal mudança não foi facilmente aceita pelos cientistas da época. A exploração do mundo atômico e subatômico os fez entrar em contato com uma nova e desafiante realidade. A teoria da relatividade e a teoria quântica trouxeram uma nova compreensão da estrutura da matéria e de que massa é energia condensada. Trouxeram, também, a necessidade de um novo olhar. Uma nova leitura de mundo se fez imprescindível, assim como uma mudança nos posicionamentos diante do mundo que se mostra e da própria vida. Como sinaliza Moraes (1997), começa a emergir a consciência da interdependência e inter-relação entre todos os fenômenos físicos, biológicos, psicológicos, culturais, sociais, assim como, naturalmente, os educacionais. Do ponto de vista individual, essa visão de totalidade implica

[...] um novo diálogo criativo entre a 'mente' e o 'corpo', entre o interior e o exterior, sujeito e objeto, hemisfério cerebral direito e esquerdo, consciente e inconsciente, indivíduo e seu contexto, ser humano e natureza. (p. 85)

Pesquisadores e estudiosos de áreas diferenciadas, nas últimas décadas, se unem na confirmação de que corpo e mente constituem uma totalidade, contrariando a visão dualista de alguns, dentre os quais, António Damásio e Humberto Maturana.

As pesquisas de Damásio (1996), que trazem um novo olhar sobre a relação corpo-mente, lançam novos desafios para a compreensão da formação do indivíduo e para pesquisas no campo da Educação. Ao questionar a dicotomia corpomente, fruto da visão cartesiana e da primazia da racionalidade, o pesquisador lança a desafiante hipótese, que desenvolve em suas pesquisas de neurobiologia, da dependência existente entre a emoção e a razão. Segundo o neurologista,

o corpo contribui para o cérebro com mais do que a manutenção da vida e com mais do que os efeitos modulatórios. Contribui com um conteúdo essencial para o funcionamento da mente normal. (p. 257)

0 autor defende a tese de que a ausência da emoção e dos sentimentos pode afetar a racionalidade, pois,

[...] os níveis inferiores do edifício neural da razão são os mesmos que regulam o processamento das emoções e dos sentimentos [...]. Esses níveis inferiores mantêm relações diretas e mútuas com o corpo propriamente dito, integrando-o desse modo na cadeia de operações que permite os mais altos vôos em termos da razão e da criatividade. (p. 233) 
Em O mistério da consciência, Damásio (2000) afirma que "as emoções são parte dos mecanismos biorreguladores com os quais nascemos equipados, visando à sobrevivência" (p. 77). Observa que, embora se considere como emoções aquelas chamadas emoções primárias ou universais (alegria, tristeza, raiva, medo...), há outros tantos comportamentos que se incluem no rol das emoções, sendo consideradas emoções secundárias ou sociais (ciúme, culpa, embaraço, orgulho entre outras). Há ainda as denominadas pelo pesquisador de emoções de fundo, como bem-estar ou mal-estar, calma ou tensão. Também se incluem sob o rótulo emoção os impulsos, as motivações e os estados de dor ou prazer. Esclarece que discutir o papel biológico das emoções é significativo para os estudos da consciência. As emoções exercem um papel biológico indispensável, pois fazem com que os organismos, automaticamente, tenham comportamentos necessários à sobrevivência. Por exemplo: o medo produz um comportamento que permite, em situações de risco, a autopreservação. A biorregulação sempre ocorre. Entretanto, quando há consciência da existência das emoções, ainda, outro nível de regulação se apresenta, como enfatiza Damásio (2000):

\section{A consciência permite que os sentimentos} sejam conhecidos e, assim, promove internamente o impacto da emoção, permite que ela, por intermédio do sentimento, permeie o processo de pensamento. Por fim, a consciência torna possível que qualquer objeto seja conhecido - o 'objeto' emoção e qualquer outro objeto - e, com isso, aumenta a capacidade do organismo para reagir de maneira adaptativa, atento às necessidades do organismo em questão. A emoção está vinculada à sobrevivência de um organismo, e o mesmo se aplica à consciência. (p. 80)

Uma série de experimentos recentes sobre o aprendizado, segundo Damásio (2000), vem fornecendo dados que corroboram o papel do corpo para a existência da emoção. Segundo essas pesquisas, tem-se considerado, também, a importância da emoção no processo de aprender, uma vez que, por meio desta, se intensifica a evocação de fatos novos durante a aprendizagem. Afirma o pesquisador que os processos mentais se relacionam com o corpo:

[...] todos esses processos - emoção, sentimento e consciência - dependem de representações do organismo. Sua essência comum é o corpo. (p. 359)

Maturana (1997) analisa a visão parcial que se tem do homem caracterizado como um ser racional. Segundo o autor, "a presença fundamental do emocionar em tudo o que fazemos, e que nos conecta com nossa história biológica de mamíferos e primatas, não é uma limitação de nossa humanidade, mas, ao contrário, é nossa condição de possibilidade enquanto seres humanos" (p. 278). Nossa cultura, devido à supervalorização da razão como uma forma de nos distinguir dos outros animais, desvaloriza as emoções. No entanto, frisa 0 autor, as emoções não restringem a razão:

[...] as emoções são dinâmicas corporais que especificam os domínios de ação em que nos movemos. Uma mudança emocional implica uma mudança de domínio de ação. Nada nos ocorre, nada fazemos que não esteja definido como uma ação de um certo tipo por uma emoção que a torna possível. (p. 92)

Para Maturana (2001), dizer que o humano é caracterizado pela razão significa um antolho, ou seja, significa a aceitação de conceitos e afirmações sem refletir sobre elas:

[...] não vemos o entrelaçamento cotidiano entre razão e emoção, que constitui nosso viver humano e não nos damos conta de que todo sistema racional tem um fundamento emocional. (p. 15) 
Damásio e Maturana, por percursos diferentes, constatam que, sem as emoções e os sentimentos, a racionalidade pode ser obstruída. o corpo dá condições para que emoções e sentimentos existam. Também estabelecem relações indissociáveis entre o biológico e o social ou cultural. Corpo, emoções e linguagem se entrelaçam na ação e nas interações. Assim sendo, minha pesquisa se assenta sobre essa compreensão de que corpo e psique são uma totalidade corpo-psique, tomando esses elementos como manifestações da mesma realidade: o ser humano. Por isso, é assumido que atuar na psique do ser humano implica reverberações no seu corpo, e atuar no corpo implica reverberações na psique, ou seja, atuar no corpo ou na psique significa atuar no ser humano como um todo. A expressividade do ser humano dá-se por meio dessa totalidade.

A seguir, dentro dessa perspectiva mais recente da pesquisa científica sobre o ser humano, considerarei autores que dão fundamentos a esta investigação. A seqüência de autores considera Wilhelm Reich como fundante desse entendimento, seguido por alguns de seus discípulos e/ ou desdobradores de seu pensamento: Alexander Lowen, Stanley Keleman e David Boadella.

\section{Wilhelm Reich e seus estudos sobre as interações mente- corpo}

$\mathrm{Na}$ área da Psicologia e da Psiquiatria, as pesquisas e a prática clínica de Wilhelm Reich abriram caminhos que vêm sendo percorridos por novos teóricos que foram enriquecendo, ampliando e aprofundando os fundamentos básicos por ele estabelecidos, entre os quais a concepção primeira de que soma e psique são partes indissociáveis.

Reich, psiquiatra austríaco e discípulo de Freud, iniciou suas atividades terapêuticas com a teoria psicanalítica em que se fundamenta boa parte de seu trabalho. Foi um dos primeiros a sistematizar a relação entre o corpo e o psiquismo na sociedade científica ocidental. Postulou a unidade funcional entre o psíquico e o somático, concluindo que a mesma energia alimenta esses dois aspectos, gerando a relação e a mútua influência entre atitudes corporais e atitudes psíquicas. Psique e corpo são faces de uma totalidade. 0 ser humano é, ao mesmo tempo, corpo e psique; dialeticamente, a psique determina o corpo e o corpo determina a psique. 0 caminho percorrido para chegar a essa concepção foi longo, cuidadoso e difícil devido às muitas pressões sofridas por parte da comunidade psicanalítica e de outros segmentos da sociedade.

Reich (1995; 1998) desenvolveu o conceito de couraças musculares ou de caráter, que são defesas criadas pelo ego, parte do indivíduo com a qual administra sua relação com o mundo. 0 caráter, para Reich, não é algo inato, mas sim uma estrutura resultante de situações vividas, de um processo de construção histórica. É com ele que vivemos nosso cotidiano, que somos e que nos relacionamos. Nossa história de vida está ligada diretamente às situações que vivenciamos, ou seja, mantém vinculação com a cultura e a sociedade em que nos formamos.

Com a restrição das expressões espontâneas, em conseqüência da necessidade de o indivíduo se adaptar ao seu meio sociocultural, ocorre a estase de energia resultante dessa contenção, ou seja, a estagnação dessa energia, que se concentrará em pontos determinados, deixando outros sem energia suficiente, provocando alterações. Essas alterações tanto ocorrem pela falta de energia em determinada parte do corpo quanto pelo excesso de energia de forma bloqueada (estase), sem movimento, sem fluidez, também, em alguma parte do corpo. A persistência de um conflito ou de conflitos semelhantes entre as próprias necessidades e o mundo externo percebido como ameaçador faz com que o ego torne-se rígido para se proteger. É nesse processo que se forma o caráter neurótico, ou seja, um modo de reação crônico, que funciona de forma automática.

É importante percebermos que a forma corporal é a marca de nossa história e qual seu significado para que tenhamos podido viver essa história. 0 conceito de couraça muscular de caráter de Reich nos ajuda nessa compreen- 
são. Criamos as couraças como formas de proteção para passar pelas várias situações que a vida nos apresenta. 0 ideal seria não tê-las, pois, embora diminuam a dor, também amortecem 0 prazer, mas elas existem para que sobrevivamos às pressões e às dificuldades com que nos confrontamos. No entanto, ter esse conhecimento é o primeiro passo para gerar transformações. Segundo Lowen (1984), discípulo de Reich,

[...] músculos tensos só podem ser liberados através de movimentos expressivos, isto é, movimentos nos quais a atividade expressa sentimentos reprimidos. Enquanto um movimento é feito mecanicamente, os impulsos reprimidos são retidos e não se consegue nenhuma liberação de tensão. (p. 53, grifos meus)

A afirmação de Lowen nos leva a entender a importância de 0 indivíduo expressar suas emoções, sua forma de ver e compreender 0 que o cerca. Quando não se tem a possibilidade de ser autêntico, de agir com espontaneidade, isso se registra no corpo mediante tensões musculares, ou seja, do encouraçamento.

Estar vivo não significa apenas ter o coração batendo, respirar e se locomover. Muito mais que isso, estar vivo se marca pela possibilidade de estar presente no mundo, de se inserir em seu movimento, de sentir, de se expressar, não se estagnando em determinados padrões ou idéias paralisantes. Corporalmente, isso se manifesta por meio da mobilidade, da respiração ritmada e profunda e do fluxo da energia corporal.

Com a perda de nossa capacidade de expressar o que sentimos e pensamos, vamos perdendo nossa autenticidade, nossa espontaneidade. Observa Lowen (1989) que a perda da autenticidade tem como conseqüência a perda da própria sensação de ser. É muito comum abrirmos mão de nossa expressão mais autêntica e assumirmos uma imagem que acabamos por aceitar como verdadeira.

0 maior fluxo de energia que gera níveis maiores de pulsação faz com que haja mais vida em nós, em nossas ações; permite maior envolvimento com as atividades que nos cabe realizar; e é o equilíbrio entre expansão e contração que gera essa possibilidade como veremos no próximo item.

\section{Contração e expansão: o}

movimento da vida

As funções biológicas fundamentais de contração e de expansão foram observadas tanto no psíquico quanto no somático. Essas duas funções básicas se relacionam com o funcionamento do sistema nervoso vegetativo ou autônomo. Esse sistema regula processos corporais básicos como respiração, pulsação cardíaca, circulação, digestão, entre outras. Sua ação foge ao controle voluntário, daí ser autônomo. Possui uma subdivisão: o sistema nervoso simpático e o parassimpático, que funcionam de forma antitética, como analisa Reich (1995):

O sistema nervoso parassimpático opera na direção da expansão 'para fora do eu, em direção ao mundo', do prazer e da alegria; ao contrário, o sistema nervoso simpático opera na direção da contração 'para longe do mundo, para dentro do eu', da tristeza, do desprazer. 0 processo vital consiste em uma contínua alternância entre expansão e contração. [...] No mais alto nível psíquico, a expansão biológica é experimentada como prazer; a contração é experimentada como desprazer. No campo dos fenômenos instintivos, a expansão funciona como uma excitação sexual, e a contração funciona como angústia. Em um nível fisiológico mais profundo, a expansão corresponde ao funcionamento parassimpático e a contração ao funcionamento simpático. (p. 245-246)

O sistema simpático, que mantém conexão com as glândulas supra-renais, mobiliza 0 corpo para enfrentar emergências, para lutar ou fugir. Diante de situações que se mostrem ameaçadoras para a pessoa, quer pela possibili- 
dade da dor ou do perigo, o simpático é ativado. Os sentidos entram em estado de alerta, as pupilas se dilatam, o coração bombeia mais sangue, a pressão sanguínea aumenta, assim como 0 consumo de oxigênio. 0 sangue é levado para o interior do corpo para oxigenar mais intensamente os órgãos vitais e a musculatura.

0 sistema parassimpático tem uma ação oposta, sua identificação com as sensações de prazer é evidente. 0 corpo se expande e a pele é irrigada pelo fluxo sangüíneo, tornando-se mais aquecida, a ação cardíaca se torna mais lenta e relaxada, a respiração mais calma e profunda, os olhos, mais brilhantes.

Essas experiências trazem para Reich a confirmação da unicidade psicofísica, ratificam o "conceito unitário do organismo". Sejam as emoções reativadas tendo como ponto de partida o psiquismo ou o corpo, são produzidos excitações e movimentos plasmáticos. 0 que se move é a energia orgone ou bioenergia, contida nos fluidos do corpo.

Com suas pesquisas, inicia-se um longo caminho de terapias bioenergéticas, de estudos e experiências que fundamentam uma nova visão do ser humano, unindo instâncias até então vistas como formas isoladas - a corporal, a emocional, a mental e a social. Reich (1995) detectou que o psíquico e o somático são dois processos paralelos que atuam reciprocamente um sobre o outro. Pôde constatar que "a estrutura psíquica é ao mesmo tempo uma estrutura biofísica que representa um estado específico indicativo da interação das forças vegetativas de uma pessoa" (p. 255). Frisa ele:

Todo impulso psíquico é funcionalmente equivalente a uma excitação somática definida. A idéia de que as funções do mecanismo psíquico funcionam apenas por si mesmas e influenciam o mecanismo somático, que também funciona por si mesmo, não está de acordo com fatos reais. (p. 290)

0 ser humano é um sujeito, sede de suas complexas interações constitutivas, cujo corpo é o arcabouço, o recurso de sua manifestação. Afinal, nele, dão-se todas as nossas vivências de sensações, movimentos, sentimentos e pensamentos. Ele é o nosso meio de estar e se expressar no mundo.

Reich (1998) considera que as palavras não são capazes de expressar plenamente 0 funcionamento do organismo vivo uma vez que este está além de todas as idéias e todos os conceitos verbais. Seu funcionamento é anterior à existência de uma linguagem e representações verbais. Afirma ele:

0 organismo vivo se expressa em movimentos; por isso falamos de movimentos expressivos. 0 movimento expressivo é uma característica inerente ao protoplasma. Distingue o organismo vivo de todos os sistemas não-vivos. [...] No sentido literal, 'emoção' significa 'mover para fora', ao mesmo tempo, é um 'movimento expressivo'. Assim, o movimento do protoplasma expressa uma emoção, e a emoção ou a expressão de um organismo está incorporada no movimento. (p. 332)

No entanto, como destaca Reich, a emoção pode se expressar mediante a imobilidade ou rigidez. Pode parecer estranho, mas se retomarmos o conceito da identidade funcional corpopsique, veremos que nos protegemos das emoções por meio das couraças musculares, que restringem nossa expressividade. Assim, a ausência de mobilidade ou de fluidez é uma forma pela qual o organismo se expressa, expressão de emoções que as palavras não são capazes de manifestar. A vida se expressa por intermédio de nosso corpo, de um maior ou menor fluxo de energia, do brilho dos olhos ou da sua opacidade, do calor da pele ou da ausência de vitalidade na mão que se estende, do prazer da convivência ou da fuga pra dentro de si mesmo.

A linguagem humana, além de sua função social de comunicação, também funciona como defesa ou como recurso de ocultamento. Isso pode ocorrer de forma consciente, o que pode ser observado facilmente na verborragia 
de políticos, nos discursos educacionais, nas mais variadas situações do cotidiano. Entretanto, a linguagem verbal pode funcionar como defesa inconsciente para que a linguagem expressiva do núcleo biológico não seja acessada. Ou seja, funciona como uma forma de evitar o contato consigo mesmo.

Para Reich (1998), o caráter pode ser genital ou neurótico. 0 primeiro caracteriza 0 ideal na perspectiva reicheana - um comportamento auto-regulado e produtivo, a capacidade de resolver conflitos de uma forma não neurótica. 0 caráter neurótico indica uma estrutura de caráter marcada pela cronificação, pela rigidez, por mecanismos repetitivos de ação e proteção automáticos, que inibem as possibilidades de mobilidade do indivíduo, portanto, inibem uma expressão mais espontânea. As vicissitudes da vida produzem o caráter, que vai expressar-se por meio do ego, que só existe enquanto o sujeito age, selecionando e controlando sua forma de ação, mesmo que de forma inconsciente. É esse sujeito que é mais fluido ou mais estático, congelado. 0 congelamento é expresso pelo caráter neurótico; a fluidez pelo caráter genital.

Falamos de um 'caráter genital' quando as reações emocionais não são regidas por um automatismo rígido, quando a pessoa é capaz de reagir de uma maneira biológica a uma situação particular. (p. 336)

Nem sempre podemos ou devemos expressar tudo que sentimos ou pensamos, mas essa é uma situação diferente daquela em que o indivíduo perde a capacidade de fazê- lo e de percebêlo. 0 organismo encouraçado não é capaz de se liberar de suas próprias couraças nem de expressar suas emoções biológicas básicas.

Como frisa Reich (1991) em 0 assassinato de Cristo, em que analisa o distanciamento do homem de si mesmo, do contato com seu centro energético, se privando das próprias fontes de vida, "não há nada mais destrutivo do que a Vida anulada e contrariada por esperanças frustradas" (p. 9). Anular a vida é, em últi- ma análise, não permitir que ela se expresse com toda sua intensidade.

A teoria de Reich e a de seus continuadores, aqui considerados, são significativas para os estudos na área da Educação, na medida em que apontam possibilidades de um novo olhar para 0 corpo na prática pedagógica e maior compreensão das relações indissociáveis entre corpo, sentimentos e pensamento. Reich sempre se preocupou em apontar a possibilidade de prevenir neuroses mediante uma mudança nas práticas educativas. Sua teoria nos ajuda, ainda, a compreender o significado das atividades expressivas na sala de aula, inclusive para a formação do educador.

Agressões e choques, situações vividas e sentidas vão se imprimindo em cada célula, criando uma imagem somática, emocional, psicológica. No entanto, o padrão assumido inconscientemente pode ser modificado, como enfatiza Keleman (1992; 1996), e duas das formas de possibilitar essa transformação são 0 cuidar de si e as atividades expressivas, que considero, em última análise, também como um cuidar-se. Cuidar de si, nesse sentido, significa dar possibilidades de que às contrações (tensões, sustos, dificuldades...) se sigam as expansões (relaxamento, acolhimento, situações prazerosas, apoio...). A ludicidade e as atividades de arteeducação oferecem possibilidades para esse processo de expansão, de restauração de um estado de inteireza, de maior centramento, de estar bem: possibilidades para a expressão própria, 0 que será considerado no próximo item.

\section{Atividades expressivas e a utocuidado: em busca da} flexibilização das couraças

A sala de aula, entre outros ambientes vitais e sociais, da mesma forma que pode ser um espaço que dá maior consistência ao encouraçamento, pode ser também um local para a flexibilização das couraças e reequilíbrio do fluxo energético do ser humano. Uma das possibilidades de promover esse reequilíbrio é a utilização das atividades expressivas na prática 
pedagógica escolar. As atividades expressivas (dentre elas estão as atividades lúdicas e as atividades de arte-educação) atuam sobre a energia, logo mobilizam soma e psique, constituindo-se em uma experiência integradora. Observa Luckesi (2000) que nosso ego, tendo em vista nossa história de vida e as agressões sofridas, se manifesta com constrições e defesas, portanto, é "controlador". As atividades expressivas propiciam que vivenciemos um estado de consciência que nos libertam temporariamente desse controle, o que permite a expressão da criatividade, ou seja, uma expressão mais original, mais própria, sem julgamentos prévios, sem os limites rígidos do perfeccionismo. $\mathrm{Na}$ verdade, elas atuam sobre a energia aprisionada, que mais equilibradas ou flexibilizadas, abrem como que brechas, possibilitando contato mais profundo conosco. Esse contato se faz, na maioria das vezes, de forma efêmera, mas mesmo sendo fugaz, permite-nos novas percepções, um maior conhecimento de nós mesmos e possibilidades de mudança.

As atividades lúdicas podem ser uma brincadeira, um jogo ou qualquer outra atividade que possibilite instaurar um estado de inteireza: uma dinâmica de integração grupal ou de sensibilização, atividades de artes plásticas (massa de modelar, recorte e colagem, desenhos, pinturas, construção de fantoches, entre outras), uma das muitas expressões dos jogos dramáticos, exercícios de relaxamento e respiração, uma ciranda, atividades rítmicas, entre outras. Mais importante, porém, do que o tipo de atividade, é a forma como é orientada e como é experienciada, e o porquê de estar sendo realizada. Ela deve permitir que cada um possa se expressar livre e solidariamente, unindo razão e emoção.

As atividades de arte-educação vêm abrindo cada vez mais espaços para pesquisas, devido a sua importância para o desenvolvimento do educando, tanto cognitivo quanto emocional e motor. A arte agiliza nossa imaginação, amplia os limites da intelecção, abre espaço para o sonho, a fantasia, para a criação de mundos possíveis, de novas possibilidades de ser e de sentir como analisa Duarte J r. (1983). Ostrower (1987) complementa essa idéia ao afirmar que

\section{[...] inata ou até mesmo inerente à constituição humana, a sensibilidade não distingue somen- te artistas ou alguns poucos privilegiados. Em si, ela é patrimônio de todos os seres huma- nos, [...] todo ser humano que nasce, nasce com um potencial de sensibilidade. (p. 12)}

No entanto, como qualquer potencial, precisa ser desenvolvido. A autora enfatiza, ainda, que "como o próprio viver, o criar é um processo existencial" (p. 56). É por meio do exercício de sua criatividade em todos os âmbitos de sua existência que o ser humano configura sua vida e lhe dá sentido.

Arte-educação e ludicidade são processos que se entrelaçam, formando uma trama de cores, formas, brilhos e sons. Uma tessitura de pensamentos, sentimentos e ações, de estímulo à criatividade, à expressão pessoal, ao contato consigo e com o outro. Envolvem adultos, jovens ou crianças, cada grupo com suas peculiaridades e necessidades expressivas, gerando entrega e integração, estimulando a percepção sensorial, soltando amarras, deixando preconceitos para trás.

Quando verbalizamos ou nos movimentamos de forma espontânea, entramos em contato com o pulsar de nossa energia, integramos corpo e psique. As atividades expressivas permitem a manifestação, em qualquer idade, daquilo que as brincadeiras infantis permitem à criança manifestar: a ação do impulso criativo, a espontaneidade do ser humano, a alegria de estar inteiro naquele momento, enfim, a autoexpressão. 0 lúdico para o adulto ou 0 adolescente não significa brincar como a criança, e sim estar imerso em sua atividade, vivenciá-la com entrega. É estar pulsando. Como observa Lowen (1984), "quando estamos identificados com uma atividade, fluímos livre e espontaneamente. 0 prazer é esse fluxo de sentimentos" (p. 23). 
Eva Reich (1998) afirma que medo e raiva contidos endurecem o organismo, contrariamente ao amor e à alegria que o suavizam. Nossos sentimentos provocam uma mobilização em nosso corpo:

Um sentimento não é uma idéia ou uma imaginação - é um acontecimento energético no corpo. Existe algo que flui dentro de nós. Quando estamos felizes, nos esticamos, nos expandimos para o mundo. Quando temos medo, nos retraímos para dentro de nós mesmos. Nesse movimento, o que flui de lá para cá é nossa energia vital. (p. 29)

As atividades expressivas propiciam que o indivíduo vivencie sua inteireza e sua autonomia em um tempo-espaço próprio, particular. Esse momento de encontro consigo mesmo gera possibilidades de maior conhecimento de si e do outro, estimulando o cuidado. Entender e vivenciar essa experiência exige a entrega, 0 que se torna inviável no fazer mecânico, no fazer por fazer.

O cuidado, como enfatiza Boff (1999), é o que se opõe ao descuido e ao descaso. Cuidar não é apenas um ato, mas uma atitude. Não se trata de apenas dedicar um momento de atenção, de zelo ou desvelo, "representa uma atitude de ocupação, preocupação, de responsabilização e de envolvimento afetivo com 0 outro" (p. 34). É a base que possibilita a existência humana enquanto humana.

Cuidar implica a busca de qualidade de vida, o investimento no próprio processo de crescimento, fundamenta-se na co-responsabilidade, na solidariedade, na ética, no respeito como qualidades fundamentais da convivência entre as pessoas.

A utilização das atividades expressivas não tem por objetivo trabalhar com o passado, mas sim mobilizar as tensões e, conseqüentemente, as emoções aprisionadas que dificultam a expressão espontânea do ser humano, aumentando sua vitalidade. Traz o sujeito para 0 momento presente, desvinculando-se do passa- do e sem se projetar no futuro, dando-Ihe a possibilidade de experimentar-se inteiro no aqui-agora, a vivenciar a plenitude da experiência, a libertar o ego que deseja controlar tudo - presente, passado, futuro. Uma proposta educativa expressiva, propiciando o encontro do sujeito consigo mesmo, pode permitir a descoberta de limites e possibilidades. 0 processo, naturalmente, tem ritmos e resultados diferenciados, dependendo da forma como cada um seja tocado pelas atividades, das situações vivenciadas ao longo da sua vida, mas as possibilidades de crescimento e reorganização interna existem. Vivenciar um presente mais pulsante, com maior fluxo de energia vital, é cuidar do futuro, prevenindo a formação de novas couraças e, também, mobilizar e transformar qualidades do passado, o que aponta para o aspecto curativo dos momentos de expressão criativa.

Como enfatiza Pereira (1992), quando temos a possibilidade de entrar em contato com nossa sensibilidade e expressá- la corporalmente, ou seja, não só por meio da verbalização, mas de gestos, de atividades artísticas e lúdicas, podemos nos libertar

[...] de padrões arraigados e castradores, tomar consciência do poder expressivo de nosso corpo, abrir infinitas perspectivas para um trabalho mais criativo, crítico, humano e prazeroso. (p. 141)

Freire (1987) enfatiza que "ninguém educa ninguém, ninguém educa a si mesmo, os homens educam- se entre si, mediados pelo mundo" (p. 52). É a abertura para a transformação, para a aprendizagem, para o desvelamento do mundo e o comprometimento com isso que propiciam a aprendizagem. A ressonância, ou seja, um ambiente propício para a espontaneidade e a aceitação, cria espaço favorável a essa abertura e a esse comprometimento. Uma prática em que estejam presentes as atividades expressivas pressupõe a humanização nas relações, a presença da ressonância. Só podemos estar presentes de fato quando nos colocamos inteiros naquilo que fazemos. 
Criar um padrão de ressonância significa estar presente, vivenciar o aqui-agora, o que se passa a nossa volta, sentir o ambiente, a energia que flui na troca com o outro. Significa estabelecer uma relação mais autêntica, deixando cair a máscara da autoridade, que se confunde com 0 autoritarismo, da pseudo-segurança, de dono da verdade. Temos muitos medos, entre eles o de perder o controle das situações, da sala de aula, de termos nosso saber colocado em xeque, de deixar que nossas fraquezas se mostrem, enfim, de que nossa humanidade seja desvelada. Esquecemos, muitas vezes, que a verdadeira autoridade é conquistada e não imposta. Ela é conquistada pelo respeito que temos por nossos educandos e que estes têm por nós, pelo comprometimento que assumimos com nosso trabalho. Falar de sentimentos, de amor, de solidariedade soa como pieguice para muitos. Vivenciá-los destrói esse mito. E as atividades expressivas são recursos que nos dão possibilidades de superar muitas das barreiras que construímos a nosso redor, como formas de nos proteger e evitar o sofrimento. Entretanto, quanto mais barricadas erguemos por medo de tornar nossa relação mais humana e mais vulnerável, mais dificuldades criamos para que a expressão criativa se manifeste, assim como maiores possibilidades de criar interferências que dificultam a dinâmica das atividades didático-pedagógicas.

É importante que haja a percepção e a consciência sobre o ser humano em si mesmo e na sua interação com as complexas relações sociais. 0 ser humano é um sujeito, sede de suas complexas interações constitutivas, cujo corpo é o arcabouço, o recurso de sua manifestação. Afinal, nele, dão-se todas as nossas vivências de sensações, movimentos, sentimentos e pensamentos. Ele é 0 nosso meio de estar e se expressar no mundo.

\section{Considerações finais}

Um aspecto muito presente nos acompanhamentos que faço a educadores já graduados durante pesquisas e àqueles que estão em formação durante seus estágios supervisionados são as queixas quanto às dificuldades institucionais - espaço físico, falta de material pedagógico, direção, coordenação, grade curricular, entre outros. Muitas vezes, esses pontos são citados como a causa da impossibilidade de uma mudança em suas práticas em sala de aula. Não se pode negar que dificuldades existem, mas sempre podemos gerar algumas transformações no espaço de nossas salas de aula dependendo de nossa visão de mundo e de educação, como muitos dos professores graduados ou em formação acabam por constatar, realizando uma prática diferenciada.

Paulo Freire (1987), em diálogo com Ira Shor, discute os muitos entraves e o medo que fazem parte do cotidiano do professor e a necessidade de ter coragem para vencer os muitos obstáculos com que nos defrontamos na prática pedagógica. Pela nossa própria formação, nós, educadores, não estamos preparados para usar o espaço da sala de aula como um espaço possível de transgredir e transformar. A vontade de mudar e o medo ou as dificuldades de investir em processos de mudança são facilmente observáveis nas mais diversas situações.

Como afirma Freire (1992), o conhecimento "requer sua ação transformadora sobre a realidade. Demanda uma busca constante. Implica invenção e reinvenção". O ser humano estabelece relações com o mundo mediante suas ações que deixam suas marcas. "Atuando, transforma: transformando, cria uma realidade que, por sua vez, 'envolvendo-o', condiciona sua forma de atuar" (p. 27-28).

Assmann (1995) afirma que "enquanto organismo vivo somos também um sistema perceptivo e cognitivo". A partir do que nos vem "de fora", se dá a nossa construção ativa da imagem do real. 0 mundo se forma, se cria somente a partir da leitura que dele fazemos, "corporalizada no sistema auto-organizativo que somos". Dessa forma, não se pode pensar a educação, a política ou a espiritualidade (nem o si mesmo, complementaria eu) sem que se tenha como referência a corporeidade.

Enfim, nenhum ideal se concebe como ideal, nenhum ideal se encaminha e nenhum 
ideal se cumpre a não ser enquanto ligado à mediação da Corporeidade dos seres deste mundo. (p. 90-91)

Não podemos dissociar a singularidade da pessoa do educador, sua história de vida e sua atuação profissional. São fios que tecem uma totalidade. Sua formação profissional, os rituais acadêmicos vividos, suas transformações pessoais, a aquisição de novos saberes irão enriquecendo a trama desse tecido que se constrói ao longo de sua vida.

A nossa capacidade expressiva exige, antes de tudo, uma percepção adequada de nós mesmos por intermédio de nosso corpo, tanto física quanto energeticamente falando, o que implica o exercício da autopercepção. Isso significa perceber as próprias emoções, a própria postura, as próprias limitações, os pontos onde se concentra tensão ou fluidez. Se não somos capazes de nos perceber e de nos apropriarmos um pouco de nós mesmos, teremos maior dificuldade em nos colocarmos no mundo com a força de nossa expressividade. Ter consciência de que nossa capacidade de expressão sofre restrições e entender o que as causa é um passo importante para sua modificação, mesmo que não seja tão simples por serem já antigas e arraigadas. E por isso mesmo, quanto mais cedo nossos educandos puderem desenvolver uma expressão mais espontânea, mais facilmente poderão desenvolver sua capacidade de usar a própria voz.

Após a análise das teorias trazidas para a construção deste trabalho, podemos retornar à questão inicialmente colocada: se houver excessiva valorização da racionalidade em detrimento da corporeidade, do sensível, do lúdico e da emoção, teremos possibilidades de exercer nosso ofício de educadores com uma visão integrada do ser humano? Certamente a resposta é não. A dissociação entre soma e psique gera uma visão fragmentada do ser humano.
Keleman (1996) observa que, geralmente, as atitudes são consideradas um conjunto mental, mas vão além disso, pois há componentes musculares, emocionais e mentais.

Se eu tiver atitudes rígidas, elas não definirão apenas o meu sistema rígido de crenças: definirão também o sistema rígido de sentimentos e o sistema rígido de ações pertencentes ao meu rígido conjunto corporal. Não é apenas meu pensamento que está densamente contido. É o meu corpo todo que não pode se mover livremente, que não pode sentir livremente. (p. 42)

As dificuldades do cotidiano, que deixam suas marcas nos corpos, revelando-se em gestos, posturas e movimentos, refletindo-se sobre a forma de ser, de atuar no dia-a-dia e de se comunicar, interferem no processo intelectual e emocional, podendo gerar formas de controle e alienação como analisa Pereira (2005). Dessa forma, é significativo que consideremos a unicidade soma-psique na formação de nossos educandos e na de nossos futuros educadores, buscando investir em pesquisas nessa direção. A unidade soma-psique, que vem sendo estudada por várias áreas de conhecimento, aponta-nos um novo caminho para a formação do ser humano, integrando pensamentos, sentimentos, movimentos e espiritualidade.

Educar significa contribuir para o crescimento do educando, para sua formação, meIhora da sua qualidade de vida, para sua autonutrição, o que significa contribuir para a sua felicidade: é, sobretudo, um ato amoroso. Boadella (1992), citando Russel e Russel, afirma que amar é propiciar ao outro o conhecimento de si mesmo. E considero que conhecer a si mesmo é o primeiro passo para adquirir recursos para lidar com as próprias dificuldades. Olhar mais para si e para o corpo significa abrir-se para o outro também e entrar em contato com possibilidades de ação e de transformação individual e coletiva. 


\section{Referências bibliográfic as}

ASSMANN, H. Paradigmas educacionais e corporeidade. 3 ed. Piracicaba: UNIMEP, 1995.

BOFF, L. Saber cuidar: ética do humano - compaixão pela terra. 4 ed. Petrópolis: Vozes, 1999.

BOADELLA, D. Correntes da vida: uma introdução à Biossíntese. Tradução de Cláudia Soares Cruz. 2 ed. São Paulo: Summus, 1992.

CAPRA, F. 0 ponto de mutação. Tradução de Álvaro Cabral. 7 ed. São Paulo: Cultrix, 1988.

DAMÁSIO, A. R. 0 erro de Descartes: emoção, razão e o cérebro humano. Tradução de Dora Vicente e Georgina Segurado. São Paulo: Companhia das Letras, 1996.

0 mistério da consciência. Tradução de Laura Teixeira Motta. São Paulo: Companhia das Letras, 2000.

DELORS, J . Educação: um tesouro a descobrir. Relatório para a UNESCO da Comissão Internacional sobre Educação para o Século XXI. 5 ed. São Paulo: Cortez; Brasília: MEC; UNESCO, 2001.

DUARTE J R., J .-F. Por que arte-educação? Campinas: Papirus, 1983.

FREIRE, P. Pedagogia da autonomia: saberes necessários à prática educativa. 29 ed. São Paulo: Paz e Terra, 2004.

. Extensão ou comunicação? Tradução de Rosisca Darcy de Oliveira. 10 ed. São Paulo: Paz e Terra, 1992.

Pedagogia do oprimido. 17 ed. Rio de J aneiro: Paz e Terra, 1987.

KELEMAN, S. Anatomia emocional: a estrutura da experiência. Tradução de Myrthes Suplicy Vieira. 3 ed. São Paulo: SummuS, 1992.

0 corpo diz sua mente. Tradução de Maya Hantower. São Paulo: Summus, 1996.

LOWEN, A. Prazer: uma abordagem criativa da vida. Tradução de Ibanez de Carvalho Filho. 6 ed. São Paulo: Summus, 1984.

Medo da vida. Tradução de Maria Sílvia Mourão Netto. São Paulo: Summus, 1989.

LUCKESI, C. C. Educação, ludicidade e prevenção das neuroses futuras: uma proposta pedagógica a partir da Biossíntese. In: . (Org.). Ludopedagogia - Ensaios 1: Educação e Ludicidade. Salvador: Gepel, 2000. v. 1, p. 9-41.

MATURANA, H. et al. (Org.). A ontologia da realidade. Belo Horizonte: Ed. UFMG, 1997.

UFMG, 2001.

Emoções e linguagem na educação e na política. Tradução de J osé Fernando Campos Fortes. Belo Horizonte: Ed.

MORAES, M. C. 0 paradigma educacional emergente. Campinas: Papirus, 1997.

OSTROWER, F. Criatividade e processos de criação. 7 ed. Petrópolis: Vozes, 1987.

PEREIRA, L. H. P. Bioexpressão: a caminho de uma educação lúdica para a formação de educadores. 2005. 403 p. Tese (Doutorado em Educação)- Faculdade de Educação da Universidade Federal da Bahia. 2005.

. Decodificação crítica e expressão criativa: seriedade e alegria no cotidiano da sala de aula. 1992. 167 p. Dissertação (Mestrado em Tecnologia Educacional)- Faculdade de Educação da Universidade Estadual do Rio de J aneiro. 1992.

REICH, W. 0 assassinato de Cristo. Tradução de Carlos Ralph Lemos Viana. 4 ed. São Paulo: Martins Fontes, 1991.

A função do orgasmo: problemas econômico-sexuais da energia biológica. Tradução de Maria da Glória Novak. 19 ed. São Paulo: Brasiliense, 1995. 
_. Análise do caráter. Tradução de Ricardo Amaral do Rego. 3 ed. São Paulo: Martins Fontes, 1998.

. Energia vital pela bioenergética suave. Tradução de Claudia Abeling. São Paulo: Summus, 1998.

THIOLLENT, M. Metodologia da pesquisa-ação. 11 ed. São Paulo: Cortez, 2002.

Recebido em 12.12.06

Aprovado em 18.02.08

Lucia Helena Pena Pereira, mestre em Educação/UERJ ; doutora em Educação/UFBA; coordenadora do NECCEL/UFSJ Núcleo de Estudos Corpo, Cultura, Expressão e Linguagens -, cadastrado no CNPq; orientadora do PIBIC (CNPq/UFS) e FAPEMIG); vice-Coordenadora do Curso de Pedagogia; é professora de Didática, Prática de Ensino, Arte-Educação e Bioexpressão. 